\title{
Capillary electrophoresis of glutathione to monitor oxidative stress and response to antioxidant treatments in an animal model
}

\author{
N. Maeso ${ }^{\text {a }}$, D. García-Martínez ${ }^{\text {a }}$, F.J. Rupérez ${ }^{\text {a }}$, A. Cifuentes ${ }^{\text {b }}$, C. Barbas ${ }^{\text {a,* }}$ \\ a Sección Química Analítica, Facultad de Farmacia, Universidad San Pablo-CEU, Urbanización Montepríncipe, \\ 28668 Boadilla del Monte, Madrid, Spain \\ ${ }^{\mathrm{b}}$ Instituto de Fermentaciones Industriales (CSIC), Juan de la Cierva 3, 28006 Madrid, Spain
}

Received 28 February 2005; accepted 15 May 2005

Available online 24 June 2005

\begin{abstract}
Glutathione plays a central role in metabolism and antioxidant defence. Several factors can influence the analytical efficiency and rapidity of the quantitative determination of glutathione. Procedures in sample pre-treatment have been compared in order to minimize analytical errors. Capillary electrophoresis has been chosen as a more adequate technique for obtaining a rapid and simple method for glutathione and glutathione disulfide determination in the blood and liver of the rat. The methods, once optimised, have been validated and applied for monitoring the oxidative stress in an animal model, such as the rat made diabetic by streptozotocin injection, when the animals are treated with antioxidants and compared with the corresponding controls.
\end{abstract}

(C) 2005 Elsevier B.V. All rights reserved.

Keywords: Glutathione; Antioxidants; Oxidative stress; Rat; Blood; Liver; In vivo assay

\section{Introduction}

Glutathione is one of the most significant components of the collective antioxidant defenses. The glutathione status of a cell (that is, the excess of reduced over oxidized glutathione) is probably one of the most accurate single indicators of the health of the cell. This crucial role of glutathione in antioxidant defense, nutrient metabolism, and regulation of essential pathways for whole body homeostasis presents a challenge, since in order to obtain significant results about its content, continuous research and a large number of samples have to be measured. Glutathione is an ubiquitous molecule that is produced in all organs, especially in the liver [1]. Nevertheless, since blood glutathione concentrations may reflect glutathione status in other less accessible tissues, measurement of both reduced (GSH) and oxidized glutathione (GSSG) in blood has been considered essential as an index of the whole

\footnotetext{
* Corresponding author. Fax: +34 913510475.

E-mail address: cbarbas@ceu.es (C. Barbas).
}

subject oxidative status and as a useful indicator of disease risk in humans.[2,3].

Due to its interest as biomarker, the literature on glutathione is very extensive in relation to both metabolic $[1,4]$ and analytical aspects. Thus, determination is commonly achieved with HPLC by using spectrophotometric [2,5-7], spectrofluorimetric [8-10], and electrochemical [11-13] detectors and more recently capillary electrophoresis (CE). Table 1 summarizes the methods found in the literature for glutathione analysis by CE in liver and blood.

However, a difficult problem in determining glutathione levels is the sample pre-treatment. Sample collection, sample preparation, protein precipitation, and any subsequent sample treatment must be carefully considered, because the oxidation of glutathione to glutathione disulfide, including protein mixed disulfides, must be minimized; otherwise erroneously low values of glutathione and high values of glutathione disulfide and mixed disulfides will be obtained. Conflicting literature values for erythrocyte, plasma, and whole blood thiol and disulfide (cysteine or GSH and cystine or GSSG) values have resulted from the use of different analytical meth- 
Table 1

Glutathione analysis by $\mathrm{CE}$

Simperione

Bample

Sample treatmen

and the serlew with heparin. MPA was added ind the sample was centrifuged

Erythrocytes in blood (rabbits) Blood was collected with heparin and centrifuged. Plasma and buffy coat were removed and the red ells were washed twice with $\mathrm{NaCl}$ isotonic solution. The red blood cells were lysed with an equal volume of cold water and NEM. The stroma were removed a Microcon-10 membrane
a centrifuationt was filtered using

Tissues: heart and liver, mitochon- $\begin{aligned} & \text { a Mample was rinsed in ice-cold saline solution. The } \\ & \text { Salon }\end{aligned}$ tissues were homogenized in PCA and KOH. The acid-soluble phases were ultrafiltered by

dria (rats) centrifugation $\begin{array}{ll}\text { Blood (humans) } & \text { Lysis and protein precipitation in EDTA and SSA. } \\ \text { The sample was vortex mixed and centrifuged }\end{array}$

Erythrocytes and miocardial tissue The blood was vortex-mixed with saponin. Sodium (dog and humans) chloride and acetonitrile were added. The tubes were chloride and acetonitrile were added.
vortex-mixed again and centrifuged

Erythrocytes in blood (humans) Blood was collected with EDTA. Blood samples were centrifuged and then washed three tim
with $\mathrm{NaCl}$. Samples were

(A) The solution was deproteinized with, TCA and EDTA

Detectors

CZEV

HPCE UV-vis $200 \mathrm{n}$

Buffer boric acid, bis-tris $(\mathrm{pH} 8.4) 20 \mathrm{kV}$.

Capillary $75 \mu \mathrm{m} \times 57 \mathrm{~cm}$. Normal polari

Buffer sodium phosphate $(\mathrm{pH} 2.5) 15 \mathrm{kV}$.

Capillary $50 \mu \mathrm{m} \times 20 \mathrm{~cm}$. Normal polarity

(n) 47 ) GSH: $486 \pm 85 \mu \mathrm{mol} / \mathrm{L}$

$(n=47)$ GSSG: $553 \pm 90 \mu \mathrm{mol} / \mathrm{L}$

G: $8.1 \pm 2.7$

[41]

Blood was collected with EDTA, or heparin, or citrate as anticoagulant. Samples were centrifuged and stored at $-20^{\circ} \mathrm{C}$. Serum and plasma were treated with thiol reducing agent (TCEP) and internal standard (N-acetylcysteine). The solutio was deproteinized with, SSA, PCA, TCA, acetonitrile or acetone, vortex mixed and centrifuged. 6-iodoacetamidofluorescein was added for derivatization

Serum and plasma (humans) Blood was collected with EDTA. Samples were treated with thiol-reducing agent (TCEP) and internal standard ( $N$-acetylcysteine). The solutio was deproteinized with acetonitrile, vortex mixed and centrifuged. 6-iodoacetamidofluorescein was

(B) The solution in water was filtered through a Microcon-10 membrane

Buffer boric acid an 3-(cyclohexylamino)-1-propanesulfonic $85 \mathrm{~cm} \times 50 \mathrm{~cm}$. Normal polarity

Buffer boric acid and 3-(cyclohexylamino)-1-propanesulfonic acid (CAPS) $(\mathrm{pH} 10)$ Voltage of $30 \mathrm{kV}$. $E_{X} 488 \mathrm{~nm} E_{\mathrm{m} 515 \mathrm{~nm}}$ Capillary $50 \mu \mathrm{cm}$
$85 \mathrm{~cm} \times 50 \mathrm{~cm}$. Normal polarity cid (CAPS) (pH 10) Voltage of $30 \mathrm{kV}$.

GSH: $8.1 \pm 2.6 \mu \mathrm{mol} / \mathrm{mg}$ GSSG:0.45 $\pm 0.15 \mu \mathrm{mol} / \mathrm{mg}$ of $30 \mathrm{kV}$. Capillary $75 \mu \mathrm{m} \times 67 \mathrm{~cm}$ GSH: $3.08 \pm 10^{-4} \mu \mathrm{mol} / \mathrm{L}$

Buffer $\left(\mathrm{NaH}_{2} \mathrm{PO}_{4}-\mathrm{Na}_{2} \mathrm{HPO}_{4}(\mathrm{pH} 5.8)\right.$ $25 \mu \mathrm{m} \times 57 \mathrm{~cm} \cdot$ Nopillary

Buffer boric acid and Tris ( $\mathrm{pH} 8.0$ ) Voltage $\quad$ Dogs $(n=6) \mathrm{GSH} \cdot 0.94 \mu \mathrm{mol} / \mathrm{L}$.

of $10 \mathrm{kV}$. Capillary $50 \mu \mathrm{m}, 30 \mathrm{~cm}$. Normal GSG:0.23 $\mu \mathrm{mol} / \mathrm{L}$. Humans polarity $(n=6) \mathrm{GSH}: 0.87$
$0.06 \mu \mathrm{mol} / \mathrm{L}$

Buffer boric acid ( $\mathrm{pH} 7.8)$ Voltage of $27 \mathrm{kV}$. Capillary $75 \mu \mathrm{m}, 37 \mathrm{~cm}$. Normal (A) GSH (4.256-1

6-10.659 $\mu \mathrm{mol} / \mathrm{g}$ haemoglobin) GSSG: $(0.302-0.507659 \mu \mathrm{mol} / \mathrm{s}$ (B) GSH haemoglobin) 
ods $[3,14]$. Main differences come from the deproteinization step [12,15-24]. Moreover, the stability of GSH and its possible oxidation to GSSG during the period between collection and analytical determination have been questioned [3].

After considering different aspects, capillary electrophoresis has been chosen as a more adequate technique for obtaining a rapid and simple method for GSH and GSSG determination in the blood and liver of the rat. The present work will focus on putting together different considerations made by different authors on sample collection, sample treatment and the method of measurement to optimize and validate an analytical method for glutathione analysis in blood and liver. The methods are then applied for monitoring the oxidative stress in an animal model, such as the rat made diabetic by streptozotocin injection [25,26], when the animals are treated with antioxidants and compared with the corresponding controls. The final purpose is to have analytical tools to evaluate the variation of metabolic parameters during in vivo studies that can correlate with the nutraceutical activity of extracts from different natural sources.

\section{Materials and methods}

\subsection{Instrumentation}

The separation was performed on a capillary electrophoresis P/ACE 5010 (Beckman, Madrid, Spain) with UV detection at $200 \pm 10 \mathrm{~nm}$. It was equipped with an uncoated capillary (Beckman, Madrid, Spain) with $47 \mathrm{~cm}$ total length (40 $\mathrm{cm}$ effective length) and $50 \mu \mathrm{m}$ i.d. and was operated at $27 \mathrm{kV}$. Temperature was maintained at $25^{\circ} \mathrm{C}$. The capillary was conditioned by rinsing in the high-pressure mode $(20 \mathrm{psi})$, in the following order: $0.1 \mathrm{M} \mathrm{NaOH}(1 \mathrm{~min})$, purified water (1 min) and running buffer (1 min). Buffer vials $(4 \mathrm{~mL})$ used for separation were replaced after every four injections.

\subsubsection{Liver}

The background electrolyte (BGE) for GSH and GSSG analysis in liver was prepared with $0.200 \mathrm{M} \mathrm{H}_{3} \mathrm{BO}_{3}$ made up $\mathrm{pH} 8.0$ with $\mathrm{NaOH}$. The current generated in such conditions was $27 \mu \mathrm{A}$. The injection was by pressure $(0.5 \mathrm{psi})$ for $5 \mathrm{~s}$.

\subsubsection{Blood}

The BGE for GSH and GSSG analysis in blood was prepared with $0.350 \mathrm{M} \mathrm{H}_{3} \mathrm{BO}_{3}$ made up $\mathrm{pH} 8.0$ with $\mathrm{NaOH}$. The current generated in such conditions was $69 \mu \mathrm{A}$. The injection was by pressure $(0.5 \mathrm{psi})$ for $10 \mathrm{~s}$.

\subsection{Chemicals}

Alpha-tocopherol (all-rac) i.e. Vitamin E, ascorbic acid (vitamin C), streptozotocin (STZ), Triolein, Tween 80, $\mathrm{N}$ ethilmaleimide (NEM) and standards were obtained from Sigma (St. Louis, MO, USA). Boric acid $85 \%$ and acetroni- trile (HPLC grade) were from Merck (Darmstadt, Germany). Sodium hydroxide and EDTA-Na2 from Panreac (Madrid, Spain). All the buffer solutions were prepared with purified water by a Milli-Qplus185 (Millipore, Billerica, MA, USA).

\subsection{Animals and samples}

Liver and whole blood for method development and validation were obtained from Sprague-Dawley rats bred in San Pablo-CEU University animal quarters. STZ $(50 \mathrm{mg} / \mathrm{kg}$ ) was administered (i.p.) to promote diabetes in the diabetic groups of animals. This day was considered Day 0 of diabetes. Three days after administration of the drug, blood glucose was estimated in a droplet obtained from the saphenous vein with an Accu-Check ${ }^{\circledR}$ system (Roche, Basel, Switzerland). Rats with glucose levels above $250 \mathrm{mg} / \mathrm{dL}$ were assigned to experimental groups.

The day of sacrifice, animals were anaesthetised with ketamine/azepromacine $(75-100 \mathrm{mg} / \mathrm{kg}$ and $2.5 \mathrm{mg} / \mathrm{kg}$, respectively) and blood was obtained by cardiac puncture in EDTA. Blood $(100 \mu \mathrm{L})$ was rapidly mixed with either cold water $(250 \mu \mathrm{L})$ plus $134.3 \mathrm{mM}$ EDTA $(50 \mu \mathrm{L})$, or with the same volume of cold water $(50 \mu \mathrm{L})$ plus $134.3 \mathrm{mM}$ EDTA $(50 \mu \mathrm{L})$ and $100 \mathrm{mM}$ NEM $(200 \mu \mathrm{L})$, depending on the experiment. The hemolysate was immediately ultrafiltered to remove proteins using a micropartition device with molecular weight $30 \mathrm{kDa}$ Microcon-30 (Milipore, Billerica, MA, EEUU) by centrifugation at $36220 \mathrm{~g}, 10 \mathrm{~min}$ in a Mikro 22R refrigerated centrifuge (Hettich, Tuttlingen, Germany). The ultrafiltrate was measured by CE immediately.

Livers were excised, placed in liquid nitrogen and kept at $-80^{\circ} \mathrm{C}$. Tissue samples were ground in liquid nitrogen and around $100 \mathrm{mg}$ were homogenized in a Potter with $4 \mathrm{ml}$ of a mixture containing $\mathrm{AcN} / \mathrm{H}_{2} \mathrm{O}(62.5: 37.5$, v/v). $800 \mu \mathrm{L}$ of the homogenate were transferred to eppendorf tubes and centrifuged at $36220 \mathrm{~g}$ for $10 \mathrm{~min}$. The supernatant was immediately measured by $\mathrm{CE}$.

The scheme for sample treatment of both blood and liver is summarised in Fig. 1.

\subsection{Experimental design}

For Experiment 1, nine diabetic rats were sacrificed after 7 days of non-controlled diabetes, and results were compared with those of nine control rats with no administration.

For Experiments 2 and 3 an antioxidant mixture was developed with $100 \mathrm{mg}$ ascorbic acid as hydrophilic antioxidant, $10 \mathrm{mg}$ alpha-tocopherol as lipophilic antioxidant, dispersed in the vehicle, made up by $100 \mathrm{mg}$ triolein and $10 \mathrm{mg}$ Tween 80 in $0.5 \mathrm{~mL}$ saline.

In Experiment 2, one single dose of mixture or vehicle was respectively administered by intragastric probe to the rats of the corresponding group $24 \mathrm{~h}$ before sacrifice, which took place 7 days after STZ administration. Therefore, four groups of animals were constituted: DX, diabetic rats with antioxidant; DV, diabetic rats with vehicle; CX, age-matched 


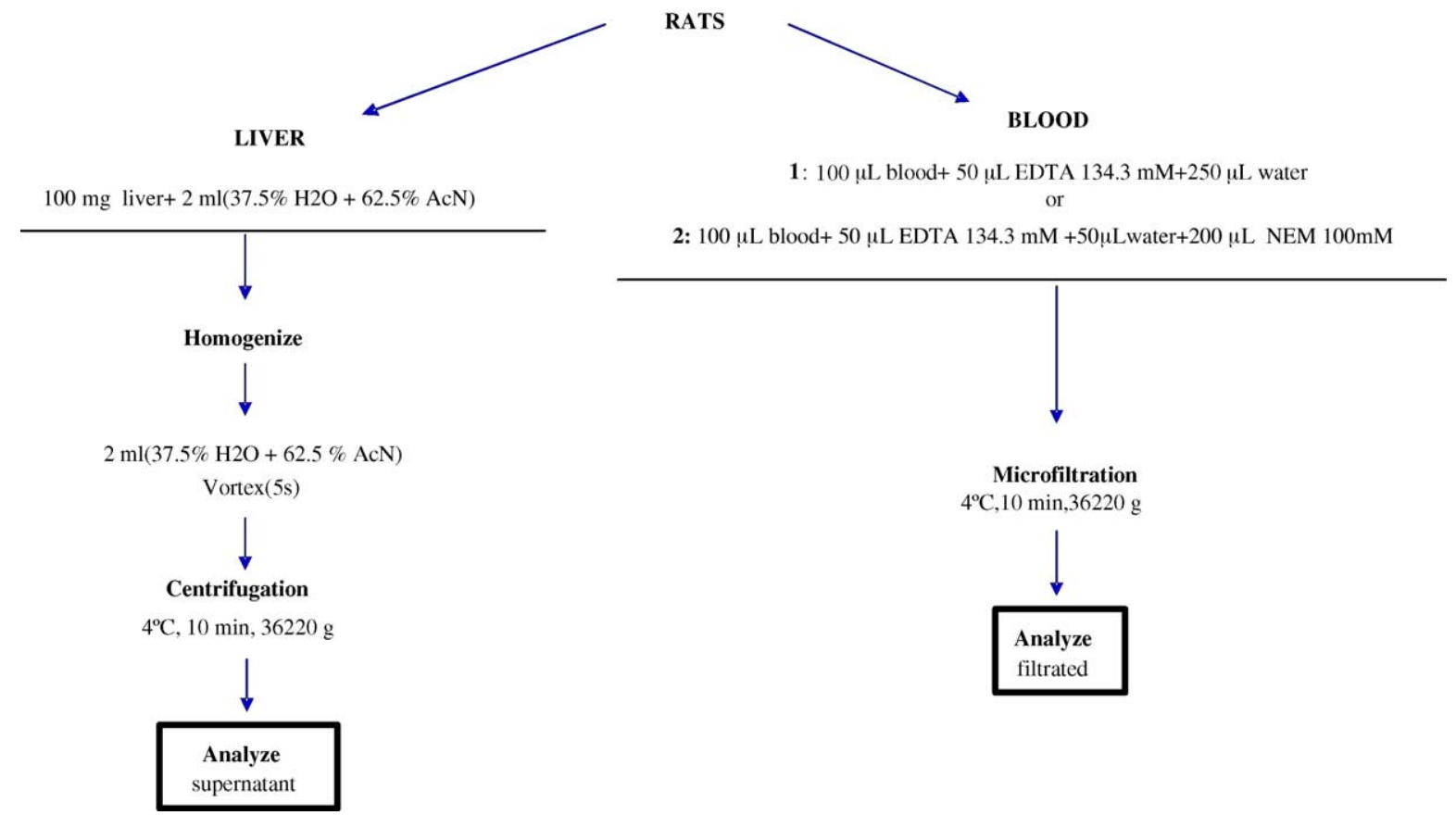

Fig. 1. Sample treatment in liver and whole blood for GSH and GSSG analysis.

healthy control rats with antioxidant; $\mathrm{CV}$, control rats with vehicle.

In Experiment 3, rats were sacrificed 1 day later than in Experiment 2 (Day 8), and they received three doses of antioxidants $(0,8$ and $24 \mathrm{~h})$, the last dose being $24 \mathrm{~h}$ before sacrifice. The groups were named following the same scheme as in Experiment 2.

The experimental protocol for the study has the approval of the animal ethics committee of our institution and it is in agreement with Amsterdam treaty and Spanish legislation (RD223/1988).

\subsection{Standards}

The standards used for quantification in blood contained $230 \mu \mathrm{M}$ GSH and $5 \mu \mathrm{M}$ GSSG in purified water containing $16.8 \mathrm{mM}$ EDTA. When NEM was employed as derivatizating agent, the standard also contained $50 \mathrm{mM}$ NEM.

For liver, standards contained $240 \mu \mathrm{M}$ GSH and $2 \mu \mathrm{M}$ GSSG in the same mixture $\mathrm{AcN} / \mathrm{H}_{2} \mathrm{O}(62.5: 37.5$, v/v) as the samples. They were prepared daily and kept cold in an ice bath.

\section{Results and discussion}

\subsection{CE separation of GSH and GSSG: method development}

Electrophoretic conditions were optimised starting from those employed by Carru et al. [20,27] for erythrocytes. Capillary length, buffer concentration, potential and $\mathrm{pH}$ were tested. Final conditions are described in the experimental section and the corresponding electropherograms can be seen in Fig. 2 for blood, Fig. 3 for blood with or without NEM and Fig. 4 for liver (vide infra).

\subsection{Effect of sample treatment on GSH/GSSG ratio determined by $C E$}

There is little consistency in the literature regarding the procedures for sample preparation employed for the measurement of glutathione in biological tissues [28]. Several authors check carefully the incidence of one particular step in the analytical process, whereas the error was introduced in the previous one. For example, precision obtained after acidic treatment with trichloroacetic acid (TCA) has been exhaustively tested [24], and, indeed, final samples are very stable, but GSH content with that treatment is much lower than with other treatments, as is shown below. Therefore, we decided to evaluate the factors affecting the method from sample collection to the measurement.

Causse and coworkers [29] demonstrated that for thiol quantification in plasma, EDTA gave better results than heparin or citrate as anticoagulant and blood samples were collected in EDTA. As for sample preparation, many different procedures can be found in literature. Some authors affirm the higher stability of GSH in samples precipitated with TCA [5], other authors maintain that metaphosphoric acid (MPA) is the best option [12], sulfosalicilic acid (SSA) and other acids are also employed [10,21]. Meanwhile, the real existence of GSSG in the samples is open to doubt [3].

Therefore, $0.1 \mathrm{M}$ TCA, acetonitrile $(\mathrm{AcN}), 0.1 \mathrm{M}$ perchloric acid (PCA), $0.1 \mathrm{M} \mathrm{HCl}, 3 \mathrm{mM}$ desferoxamine (DF), 


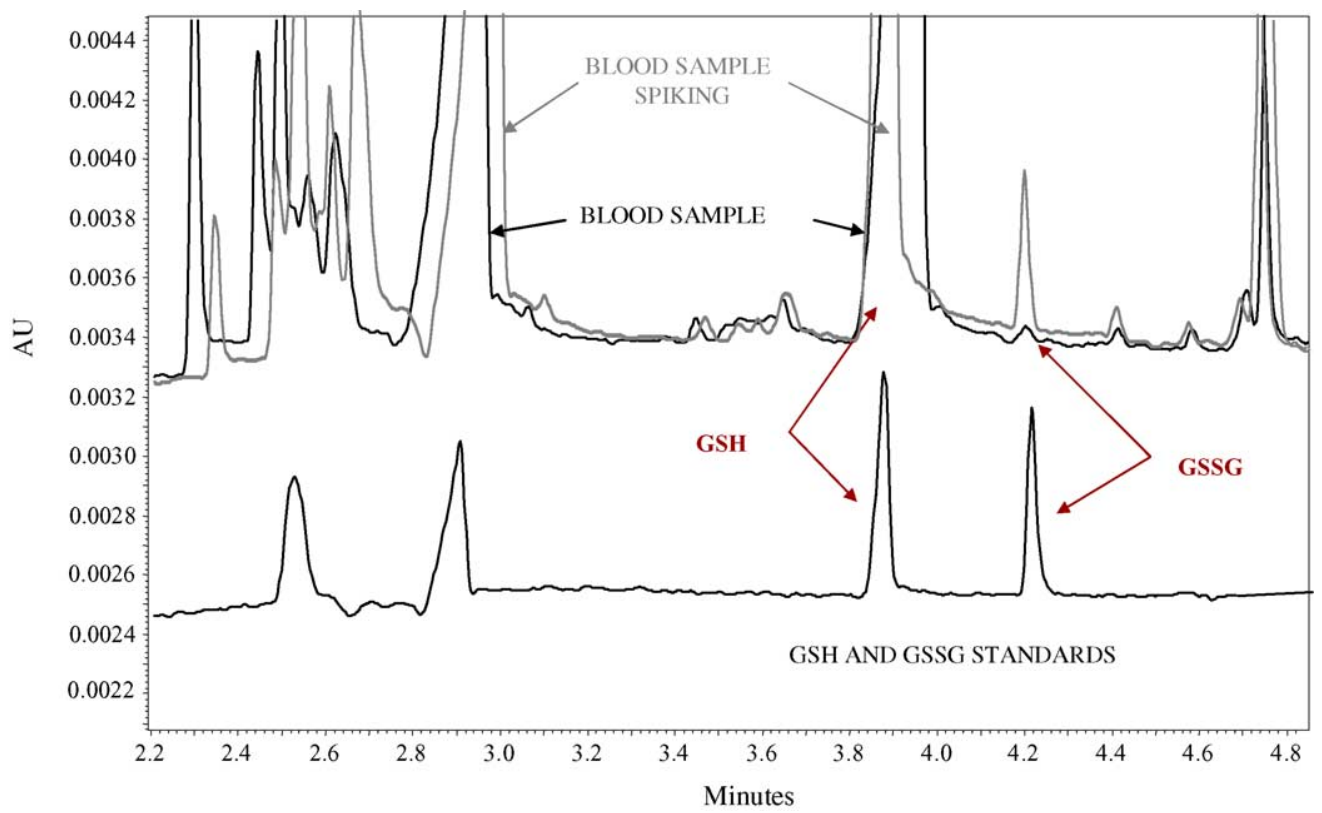

Fig. 2. Electropherograms for GSH and GSSG standards (lower); rat blood without NEM (medium); rat blood with standards added (upper). Conditions: UV detection at $200 \mathrm{~nm}$, voltage $27 \mathrm{kV}$, capillary untreated $47 \mathrm{~cm}$ and $50 \mu \mathrm{m}$ i.d., $350 \mathrm{mM}$ borate buffer at $\mathrm{pH} 8.0$.

$16.8 \mathrm{mM}$ EDTA and only cold water were tested to produce cell lysis followed by microfiltration to eliminate proteins (see Table 2). Also, $0.4 \mathrm{M}$ TCA and AcN were assayed without microfiltration (see Table 2). Blood was mixed with the corresponding reagent $1 / 3(\mathrm{v} / \mathrm{v})$. Results of this study are given in Table 2, where a higher ratio GSH/GSSG was the parameter employed for optimization. As previously described [5], 0.4 TCA provided high reproducibility and the highest values when comparing acidic precipitation, that is the reason why a large number of samples was assayed. Nevertheless, the GSH/GSSG levels were one order of magnitude lower with protein precipitation than with only cold water and values increased when water contained EDTA. This effect could be related not only to the ability of EDTA for metal complexation, also present in desferoxamine, but also to the increase in the osmotic fragility of erythrocytes, the extent of red blood cell haemolysis produced by osmotic stress, previously described [30]. Therefore, cold water with EDTA, for

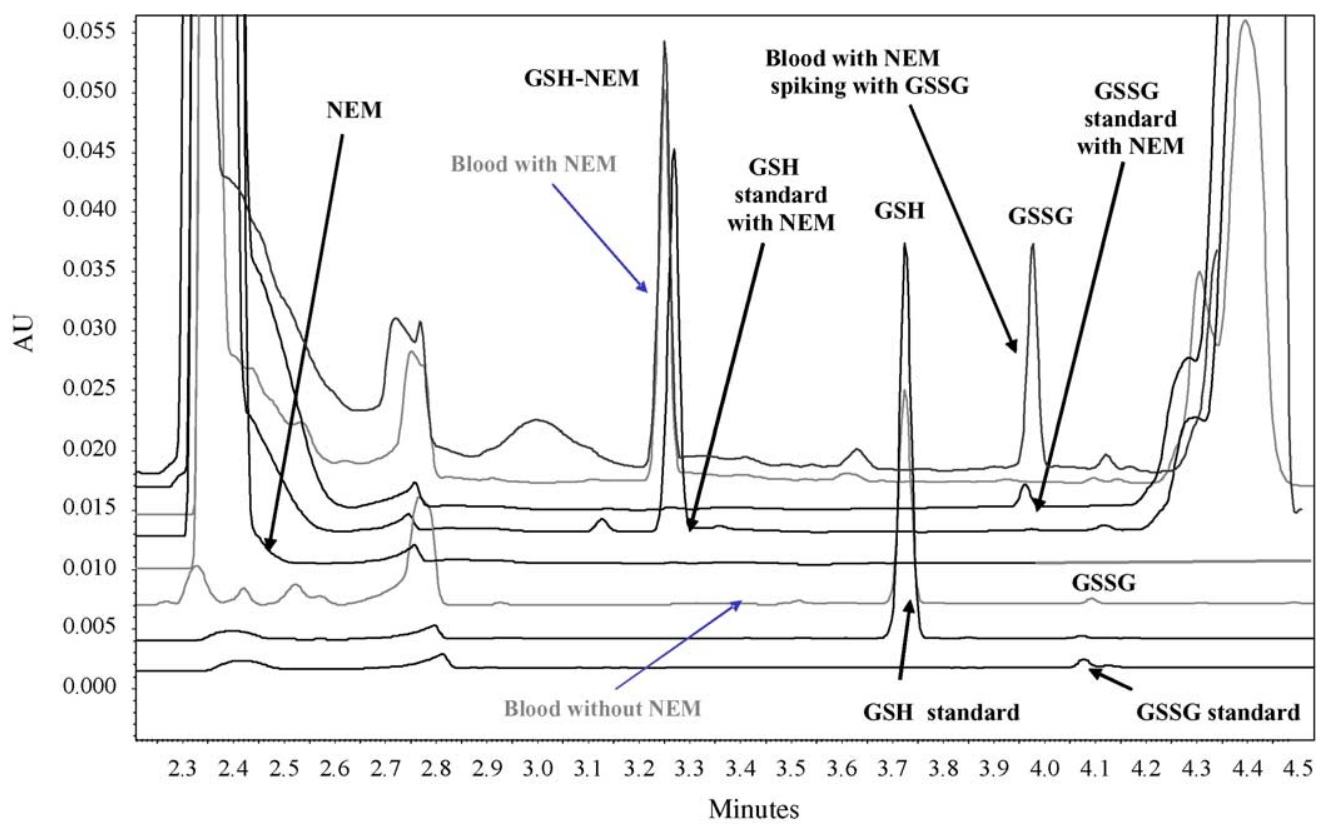

Fig. 3. From lower to upper level: electropherogram of GSSG standard; GSH standard; whole blood treated with water; NEM standard, GSH standard with NEM; GSSG standard with NEM; blood with NEM and blood with NEM spiked with GSSG. For condition see the text. 


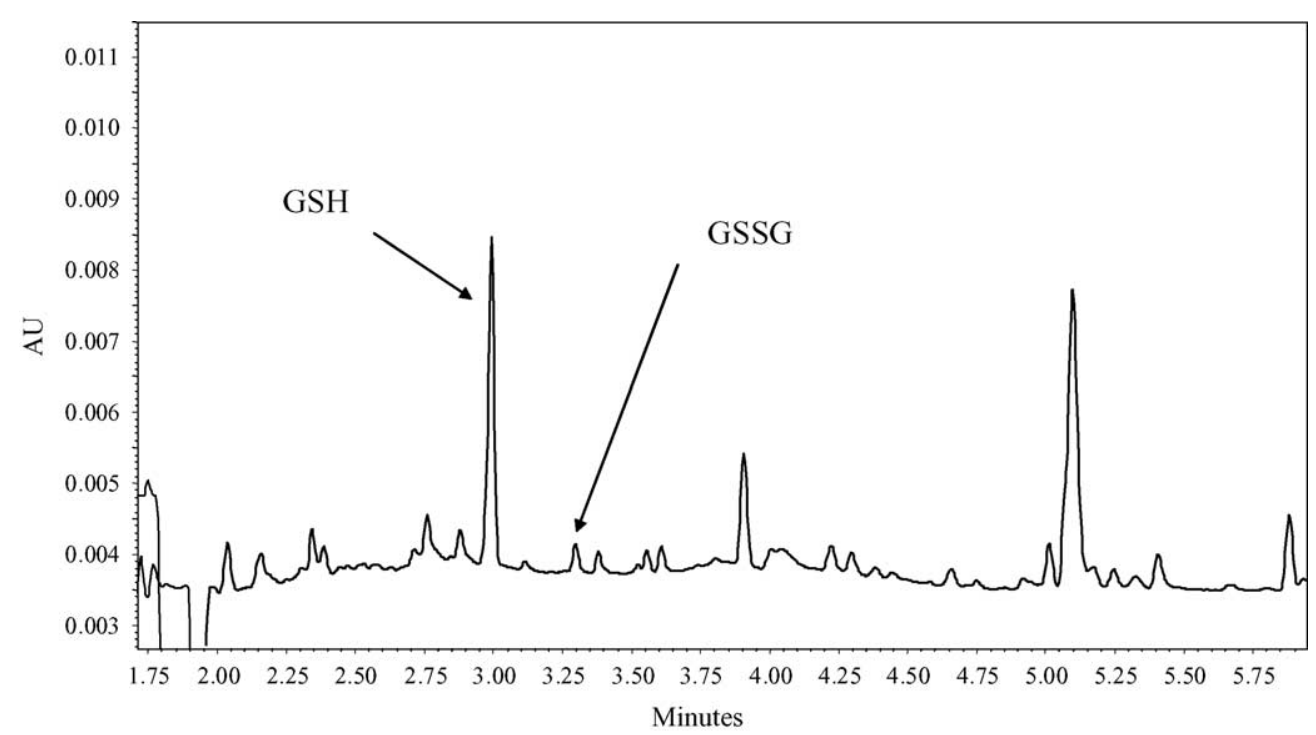

Fig. 4. Electropherograms of rat liver at $200 \mathrm{mM}$ borate buffer at $\mathrm{pH}$ 8.0. For other conditions see the text.

haemolysis, and ultrafiltration was the method selected for sample pre-treatment. There were still two aspects to confirm: the selectivity of the method for GSH, that is to demonstrate that the peak corresponds only to GSH, and that the GSH oxidation is really prevented with the working conditions. With these purposes NEM was employed [31,32] because it gives a rapid and quantitative reaction at room temperature with $\mathrm{SH}$ groups. Results can be observed in Fig. 2. When NEM was added to blood samples the GSH completely disappeared, therefore, selectivity was proved. Moreover, no differences were found in GSSG concentration when NEM was present or not.

Regarding liver treatment, samples were homogenised in pure water or water containing different proportions of methanol or acetonitrile. Our results confirmed those previously obtained by Shihabi et al. [33], the supernatant was more clear and the electrophoretic profile better defined with $62.5 \% \mathrm{AcN}$ in the mixture. Moreover, the presence of EDTA, ascorbic acid or a mixture of EDTA and ascorbic acid in the

Table 2

GSH/GSSG ratio obtained in blood samples with different treatments using precipitation and microfiltration (mean \pm S.E.)

\begin{tabular}{lc}
\hline Reagents & GSH/GSSG \\
\hline Microfiltration & \\
AcN $(n=3)$ & $3.43 \pm 0.4$ \\
TCA, $0.1 \mathrm{M}(n=2)$ & $18 \pm 5$ \\
PCA, $0.1 \mathrm{M}(n=2)$ & $1.1 \pm 0.3$ \\
$\mathrm{HCl}, 0.1 \mathrm{M}(n=2)$ & $0.4800 \pm 0.0008$ \\
Desferoxamine, $3 \mathrm{mM}(n=4)$ & $7.00 \pm 0.32$ \\
$\mathrm{H}_{2} \mathrm{O}-\mathrm{EDTA}, 16.79 \mathrm{mM}(n=10)$ & $171.0 \pm 22.5$ \\
$\mathrm{H}_{2} \mathrm{O}(n=4)$ & $70 \pm 23$ \\
Precipitation & \\
TCA, $0.4 \mathrm{M}(n=13)$ & $4.0 \pm 0.6$ \\
AcN $(n=2)$ & $8.2 \pm 0.4$ \\
\hline
\end{tabular}

aqueous part was tested. Results for 6 replicates can be seen in Table 3. The presence of ascorbic acid decreased GSH concentration, and that is justified because GSH protects ascorbic acid from oxidation $[34,35]$. There was no difference between water alone or with EDTA, therefore liver was treated with pure water and AcN as previously described by other authors $[5,8,28,36,37]$.

\subsection{Determination of $G S H / G S S G$ in real samples: method validation}

Table 4 includes the results obtained for the main validation parameters for both GSH and GSSG in blood with and without NEM and Table 5 for liver.

Linearity has been determined by a series of two replicates of five levels of standards whose concentrations span up around 50-200\% of the expected concentration range. As can be seen in Table 3, the linear regression equation applied to the results gave an intercept not significantly different from zero. The slopes are different from zero in all cases and correlation coefficients are over 0.99 in all cases. Sample linearity and recovery were estimated comparing the values obtained in the linearity test for spiked samples with the corresponding standards linearity, taking into account the initial sample concentrations, which had been previously quantified. It is

Table 3

GSH/GSSG ratio obtained in liver samples with different treatments (mean \pm S.E.)

\begin{tabular}{lc}
\hline Reagents & GSH/GSSG \\
\hline $\mathrm{H}_{2} \mathrm{O}(n=6)$ & $27.2 \pm 3.2$ \\
Ascorbic acid, $25 \mathrm{mM}(n=6)$ & $21.36 \pm 0.96$ \\
EDTA, $16.8 \mathrm{mM}(n=6)$ & $25.8 \pm 2.0$ \\
Ascorbic acid, 25 mM +EDTA $14.9 \mathrm{mM}(n=6)$ & $19.9 \pm 0.7$ \\
\hline
\end{tabular}


Table 4

Main validation parameters for the analytical method for the determination and quantification of GSH and GSSG in rat liver

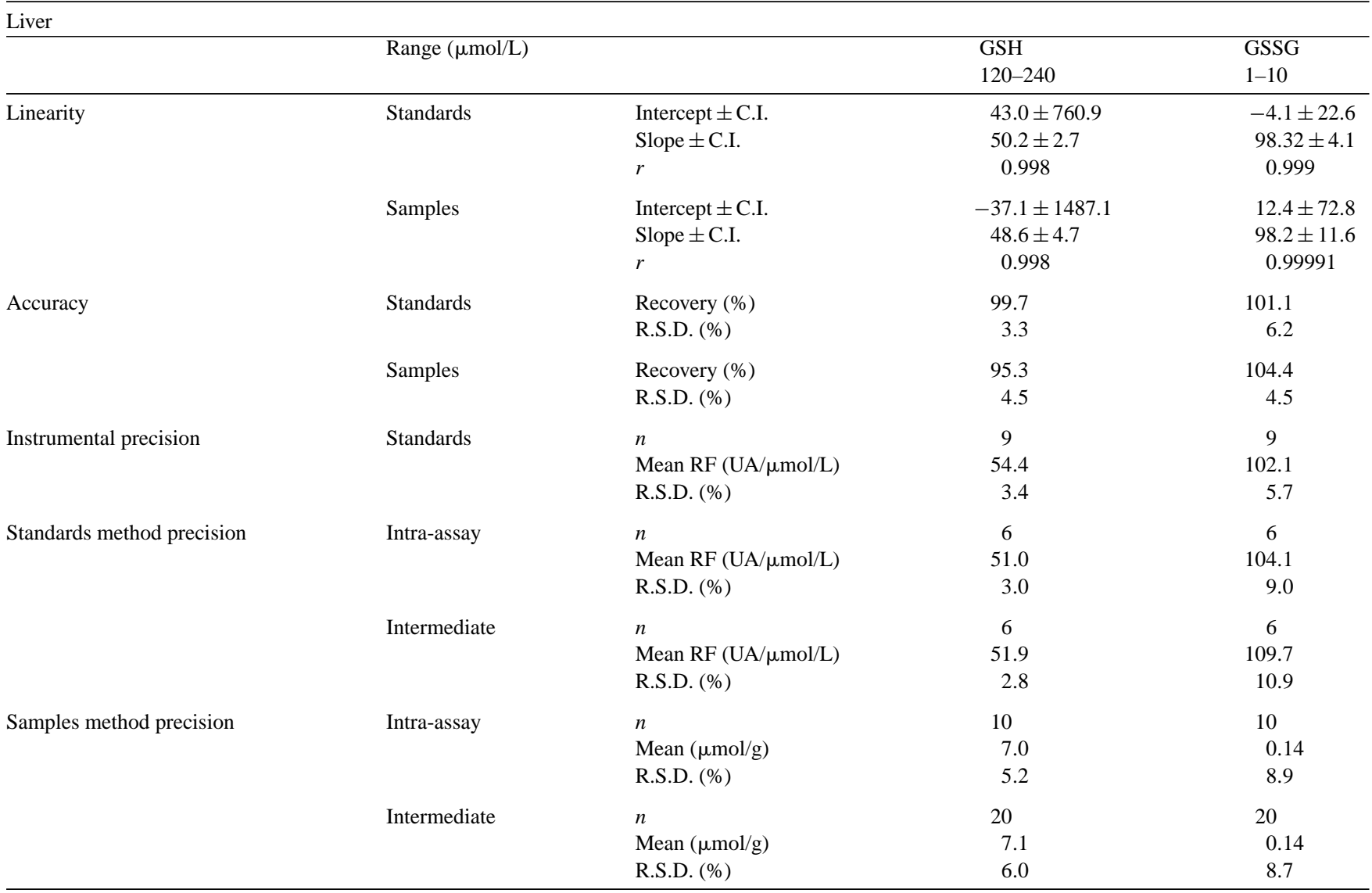

Table 5

Main validation parameters for the analytical method for the determination and quantification of GSH and GSSG in rat blood

\begin{tabular}{|c|c|c|c|c|c|c|}
\hline & \multicolumn{2}{|c|}{ Range ( $\mu \mathrm{mol} / \mathrm{L})$} & \multicolumn{2}{|c|}{ Whole blood without NEM } & \multicolumn{2}{|c|}{ Whole blood with NEM } \\
\hline & & & $\begin{array}{l}\text { GSH } \\
120-361 \\
\end{array}$ & $\begin{array}{l}\text { GSSG } \\
2.6-7.8 \\
\end{array}$ & $\begin{array}{l}\text { GSH } \\
115-460\end{array}$ & $\begin{array}{l}\text { GSSG } \\
2.6-9.9 \\
\end{array}$ \\
\hline \multirow[t]{2}{*}{ Linearity } & Standards & $\begin{array}{l}\text { Intercept } \pm \text { C.I. } \\
\text { Slope } \pm \text { C.I. } \\
r\end{array}$ & $\begin{array}{c}-472.5 \pm 1893.8 \\
132.8 \pm 7.4 \\
0.998\end{array}$ & $\begin{array}{l}-85.9 \pm 178.2 \\
255.3 \pm 38.3 \\
0.995\end{array}$ & $\begin{array}{l}480.1 \pm 999.5 \\
209.9 \pm 4.5 \\
0.9995\end{array}$ & $\begin{array}{c}-87.7 \pm 101.2 \\
439.3 \pm 20.4 \\
0.998\end{array}$ \\
\hline & Samples & $\begin{array}{l}\text { Intercept } \pm \text { C.I. } \\
\text { Slope } \pm \text { C.I. } \\
r\end{array}$ & $\begin{array}{l}932.2 \pm 1684.3 \\
121.1 \pm 6.5 \\
\quad 0.998\end{array}$ & $\begin{array}{l}-74.8 \pm 74.5 \\
263.8 \pm 17.9 \\
0.998\end{array}$ & $\begin{array}{c}1983.6 \pm 2332.1 \\
192.3 \pm 7.9 \\
0.998\end{array}$ & $\begin{array}{l}-16.58 \pm 202.1 \\
431.9 \pm 36.3 \\
0.998\end{array}$ \\
\hline \multirow[t]{2}{*}{ Accuracy } & Standards & $\begin{array}{l}\text { Recovery }(\%) \\
\text { R.S.D. }(\%)\end{array}$ & $\begin{array}{r}99.9 \\
2.6\end{array}$ & $\begin{array}{r}100.1 \\
3.0\end{array}$ & $\begin{array}{l}99.3 \\
1.04\end{array}$ & $\begin{array}{r}102.2 \\
3.5\end{array}$ \\
\hline & Samples & $\begin{array}{l}\text { Recovery }(\%) \\
\text { R.S.D. }(\%)\end{array}$ & $\begin{array}{r}95.2 \\
2.5\end{array}$ & $\begin{array}{r}83.6 \\
3.7\end{array}$ & $\begin{array}{r}93.7 \\
1.4\end{array}$ & $\begin{array}{r}102.0 \\
5.5\end{array}$ \\
\hline Instrumental precision & & $\begin{array}{l}n \\
\text { Mean RF }(\mathrm{UA} / \mu \mathrm{mol} / \mathrm{L}) \\
\text { R.S.D. }(\%)\end{array}$ & $\begin{array}{r}10 \\
131.4 \\
2.6\end{array}$ & $\begin{array}{r}6 \\
263.0 \\
2.5\end{array}$ & $\begin{array}{r}10 \\
215.6 \\
1.7\end{array}$ & $\begin{array}{r}6 \\
519.1 \\
7.8\end{array}$ \\
\hline Standards method precision. & Intra-assay & $\begin{array}{l}n \\
\text { Mean RF }(\mathrm{UA} / \mu \mathrm{mol} / \mathrm{L}) \\
\text { R.S.D. }(\%)\end{array}$ & $\begin{array}{r}6 \\
135.4 \\
1.2\end{array}$ & $\begin{array}{r}6 \\
266.3 \\
5.6\end{array}$ & $\begin{array}{r}6 \\
211.0 \\
0.7\end{array}$ & $\begin{array}{r}6 \\
495.1 \\
7.3\end{array}$ \\
\hline Samples method precision & Intra-assay & $\begin{array}{l}n \\
\text { Mean }(\mu \mathrm{mol} / \mathrm{L}) \\
\text { R.S.D. }(\%)\end{array}$ & $\begin{array}{r}10 \\
903.8 \\
1.4\end{array}$ & $\begin{array}{l}10 \\
8.5 \\
6.4\end{array}$ & $\begin{array}{r}6 \\
1017.8 \\
4.4\end{array}$ & $\begin{array}{c}6 \\
18.5 \\
3.4\end{array}$ \\
\hline
\end{tabular}


Table 6

GSH and GSSG concentrations reference values in rat blood

\begin{tabular}{lll}
\hline Experimental values & Reference values & Ref. \\
\hline & GSH:1378.0 $\mu \mathrm{mol} / \mathrm{L} ;$ & {$[2]$} \\
GSH: $903-1017.8 \mu \mathrm{mol} / \mathrm{L} ;$ & GSSG:3.21 $\mu \mathrm{mol} / \mathrm{L}$ & \\
GSSG: $7.5-18.5 \mu \mathrm{mol} / \mathrm{L}$ & GSH: $744.0 \mu \mathrm{mol} / \mathrm{L} ;$ & {$[45]$} \\
& GSSG:132.0 $\mu \mathrm{mol} / \mathrm{L}$ & \\
& GSH: $991 \pm 184 \mu \mathrm{mol} / \mathrm{L}$ & {$[46]$} \\
& GSSG: $19.3 \mu \mathrm{mol} / \mathrm{L}$ & {$[5]$} \\
\hline
\end{tabular}

curious to point out that a $95.3 \%$ GSH recovery in liver samples is compensated with a $104.4 \%$ GSSG recovery, which indicates a minor oxidation in GSH during sample treatment (Table 6).

In blood samples, the lower recovery was obtained for GSSG when only water was added $(83.6 \%)$ and could be related to the rapid reaction of enzymes that destroy GSSG, which is highly toxic for the organism. Nevertheless, GSSG loss is much lower than GSH loss when acidic media is employed to deactivate these enzymes. On the other hand, the possible modification of GSH/GSSG equilibrium when NEM is present due to the decrease in GSH concentration, discussed by some authors [3], does not seem to take place, looking at GSSG recoveries in the presence of NEM.

Therefore, validation parameters and manipulation aspects made the method with NEM more reliable for blood analysis.

Precision provided R.S.D. values, which were under 10\% in all cases. This was the acceptance criterion, considering the characteristics of samples and analytes.

Six blood samples were analysed with both methods and results were compared with data in bibliography for the same type of samples. They are summarised in Table 5. There were no significant differences (Student's $t$-test, $p<0.05$ ) between results obtained with both methods and all of them were in the range of results in bibliography except for GSSG by Asensi et al. [5]. As blood proved to be the more complicated matrix, some additional assays were developed. Blood samples were stable for no more than $30 \mathrm{~min}$ when stored in ice without any treatment, but stability increased to over $3 \mathrm{~h}$ when NEM was added after collection. Longer storage times are not recommended because NEM can slowly react with amino groups giving a decrease in the GSH-NEM peak and additional or possible interfering peaks $[2,3,5]$. Stability was established when responses varied less than $5 \%$ for GSH or $10 \%$ for GSSG, related to $t=0$.

Blood has to be analysed fresh, but liver samples can be stored at $-80^{\circ} \mathrm{C}$, therefore the stability of stored samples was also checked by comparing the values obtained for GSH and GSSG in a fresh sample and in aliquots of the same liver measured at 7, 14, 28 and 30 days. No differences were found in the results and therefore, liver samples can be stored for at least 1 month at $-80^{\circ} \mathrm{C}$ for glutathione analysis.

LODs, calculated following EURACHEM method [38] were below the expected values for both the analytes in the samples.

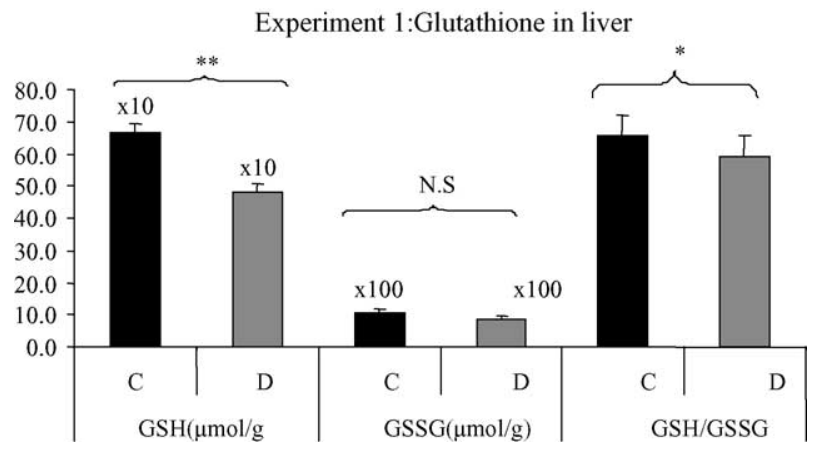

Fig. 5. GSH, GSSG, and the ratio GSH/GSSG in control and diabetic rat liver for the Experiment $1 .\left({ }^{*} p<0.05 ;{ }^{* *} p<0.01\right)$. N.S.: non-significant; C: control rats; D: diabetic rats.

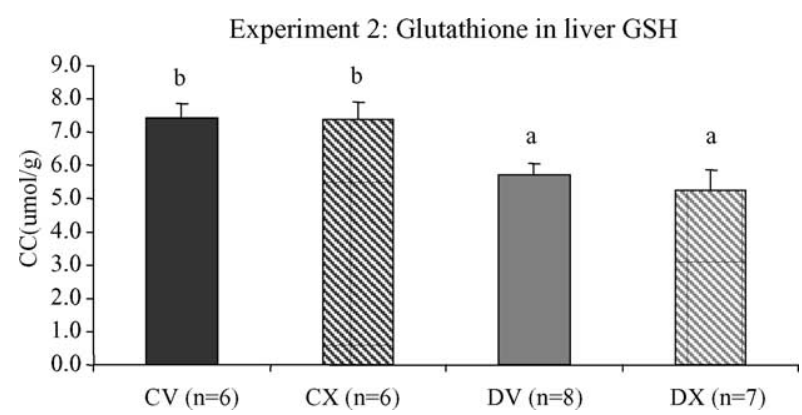

Fig. 6. GSH in control and diabetic rat liver for the Experiment 2. The same letters indicate homogeneicity of the means after multiple range test $(p<0.05)$. Abbreviations: $\mathrm{CV}$, control rats with vehicle; $\mathrm{CX}$, age-matched healthy control rats with antioxidant; DV, diabetic rats with vehicle; DX, diabetic rats with antioxidant.

\subsection{GSH/GSSG for animals under antioxidant treatments}

Results obtained with the experimental design described above in liver are summarised in Figs. 5-7. Results from control and diabetic animals (Experiment 1; Fig. 5) were statistically compared with a Student's $t$-test and showed a significant higher amount $(p<0.01)$ of GSH in control than in the liver of diabetic animals. Meanwhile, the effect of one and three doses of antioxidants was compared with the

Experiment 3:Glutathione in liver GSH

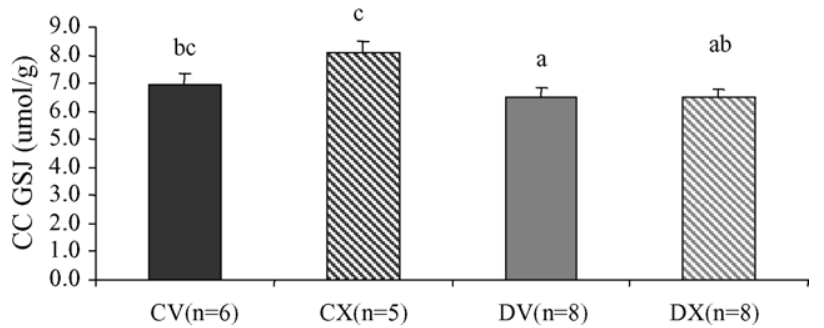

Fig. 7. GSH in control and diabetic rat liver for the Experiment 3. The same letters indicate homogeneicity of the means after multiple range test $(p<0.05)$. Abbreviations: $\mathrm{CV}$, control rats with vehicle; $\mathrm{CX}$, age-matched healthy control rats with antioxidant; DV, diabetic rats with vehicle; DX, diabetic rats with antioxidant. 
Experiment 3:Glutathione in whole blood GSH

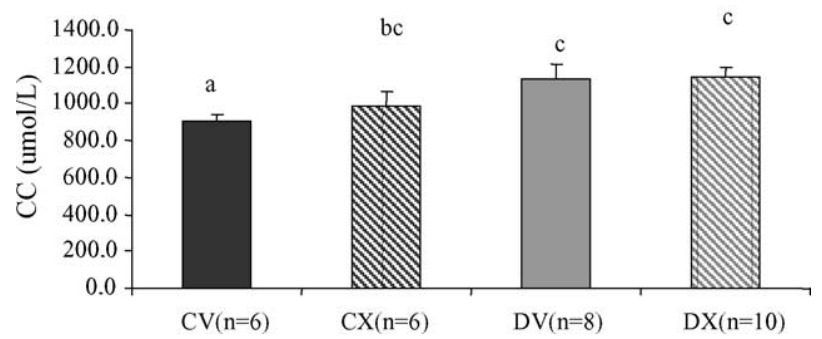

Fig. 8. GSH in control and diabetic rat whole blood for the Experiment 3. The same letters indicate homogeneicity of the means after multiple range test $(p<0.05)$. Abbreviations: $\mathrm{CV}$, control rats with vehicle; $\mathrm{CX}$, age-matched healthy control rats with antioxidant; DV, diabetic rats with vehicle; DX, diabetic rats with antioxidant.

Bonferroni multiple-range test after one-way ANOVA. One dose of antioxidant showed no change in GSH of control versus diabetic animals (Experiment 2; Fig. 6), however, when three doses were administered GSH in the liver of diabetic animals was not different to the values in controls (Experiment 3; Fig. 7).

Gluthathione in blood was measured only in the experiment with three doses, because samples cannot be stored and the method was not validated for previous experiments. It is noteworthy in Fig. 8 that GSH was significantly increased in diabetic animals versus their controls. That was previously observed by Kondo et al. [39] and could be justified by an increased endogenous synthesis [40].

\section{Acknowledgement}

\section{MCYT Project AGL2002-04621-C02-01.}

\section{References}

[1] A. Pastore, G. Federici, E. Bertini, F. Piemonte, Clin. Chim. Acta 333 (2003) 19

[2] D. Giustarini, I. Dalle-Donne, R. Colombo, A. Milzani, R. Rossi, Free Radic. Biol. Med. 35 (2003) 1365.

[3] R. Rossi, A. Milzani, I. Dalle-Donne, D. Giustarini, L. Lusini, R. Colombo, P. Di Simplicio, Clin. Chem. 48 (2002) 748.

[4] G. Wu, Y.Z. Fang, S. Yang, J.R. Lupton, N.D. Turner, J. Nutr. 134 (2004) 489.

[5] M. Asensi, J. Sastre, F.V. Pallardo, J. Garcia de la Asuncion, J.M. Estrela, J. Vina, Anal. Biochem. 217 (1994) 323.

[6] T. Yoshida, J. Chromatogr. B 678 (1996) 157.

[7] S. Ohmori, T. Kawase, M. Higashiura, Y. Chisaka, K. Nakata, Y. Yamasaki, J. Chromatogr. B 762 (2001) 25.

[8] C.C. Yan, R.J. Huxtable, J. Chromatogr. B 672 (1995) 217.

[9] C. Cereser, J. Guichard, J. Drai, E. Bannier, I. Garcia, S. Boget, P. Parvaz, A. Revol, J. Chromatogr. B 752 (2001) 123.
[10] A. Pastore, F. Piemonte, M. Locatelli, A. Lo Russo, L.M. Gaeta, G. Tozzi, G. Federici, Clin. Chem. 47 (2001) 1467.

[11] N.C. Smith, M. Dunnett, P.C. Mills, J. Chromatogr. B 673 (1995) 35.

[12] B.J. Mills, J.P. Richie Jr., C.A. Lang, Anal. Biochem. 184 (1990) 263.

[13] W.A. Kleinman, J.P. Richie Jr., J. Chromatogr. B 672 (1995) 73.

[14] E. Camera, M. Picardo, J. Chromatogr. B 781 (2002) 181.

[15] A.R. Ivanov, I.V. Nazimov, L.A. Baratova, J. Chromatogr. A 870 (2000) 433.

[16] S. Melnyk, M. Pogribna, I. Pogribny, R.J. Hine, S.J. James, J. Nutr. Biochem. 10 (1999) 490.

[17] M.W. Davey, G. Bauw, M. Van Montagu, J. Chromatogr. B 697 (1997) 269

[18] E. Camera, M. Rinaldi, S. Briganti, M. Picardo, S. Fanali, J. Chromatogr. B 757 (2001) 69.

[19] A.F. Loughlin, G.L. Skiles, D.W. Alberts, W.H. Schaefer, J. Pharm. Biomed. Anal. 26 (2001) 131.

[20] C. Carru, A. Zinellu, G.M. Pes, G. Marongiu, B. Tadolini, L. Deiana, Electrophoresis 23 (2002) 1716 .

[21] G. Piccoli, M. Fiorani, B. Biagiarelli, F. Palma, L. Potenza, A. Amicucci, V. Stocchi, J. Chromatogr. A 676 (1994) 239.

[22] S. Velury, S.B. Howell, J. Chromatogr. 424 (1988) 141.

[23] C. Bayle, C. Issac, R. Salvayre, F. Couderc, E. Causse, J. Chromatogr. A 979 (2002) 255.

[24] D. Stempak, S. Dallas, J. Klein, R. Bendayan, G. Koren, S. Baruchel, Ther. Drug Monit. 23 (2001) 542.

[25] H. Raza, A. John, Diabetes Metab. Res. Rev. 20 (2004) 72.

[26] H.J. Choi, H.D. Je, J.H. Jeong, Y.S. Min, T.S. Choi, J.H. Park, C.Y. Shin, U.D. Sohn, Arch. Pharm. Res. 26 (2003) 237.

[27] C. Carru, A. Zinellu, S. Sotgia, G. Marongiu, M.G. Farina, M.F. Usai, G.M. Pes, B. Tadolini, L. Deiana, J. Chromatogr. A 1017 (2003) 233.

[28] J.C. Roberts, D.J. Francetic, Anal. Biochem. 211 (1993) 183.

[29] E. Causse, C. Issac, P. Malatray, C. Bayle, P. Valdiguie, R. Salvayre, F. Couderc, J. Chromatogr. A 895 (2000) 173.

[30] M. Kafka, T. Yermiahu, Clin. Lab. Haematol. 20 (1998) 213.

[31] F. Tietze, Anal. Biochem. 27 (1969) 502.

[32] S.K. Srivastava, E. Beutler, Anal. Biochem. 25 (1968) 70.

[33] Z.K. Shihabi, J. Chromatogr. A 652 (1993) 471.

[34] A. Meister, Cancer Res. 54 (1994) 1969s.

[35] A.T. Diplock, Mol. Asp. Med. 15 (1994) 293.

[36] J. Lakritz, C.G. Plopper, A.R. Buckpitt, Anal. Biochem. 247 (1997) 63.

[37] T. Mourad, K.L. Min, J.P. Steghens, Anal. Biochem. 283 (2000) 146.

[38] EURACHEM, vol. guide 25, 1993.

[39] T. Kondo, Y. Higashiyama, S. Goto, T. Iida, S. Cho, M. Iwanaga, K. Mori, M. Tani, Y. Urata, Free Radic. Res. 31 (1999) 325.

[40] J.P. Bolanos, P. Garcia-Nogales, A. Almeida, Curr. Pharm. Des. 10 (2004) 867

[41] V. Serru, B. Baudin, F. Ziegler, J.P. David, M.J. Cals, M. Vaubourdolle, N. Mario, Clin. Chem. 47 (2001) 1321.

[42] C. Muscari, M. Pappagallo, D. Ferrari, E. Giordano, C. Capanni, C.M. Caldarera, C. Guarnieri, J. Chromatogr. B 707 (1998) 301.

[43] Q. Weng, W. Jin, J. Chromatogr. A 971 (2002) 217.

[44] Z.K. Shihabi, M.E. Hinsdale, C.P. Cheng, Electrophoresis 22 (2001) 2351.

[45] D.J. Reed, J.R. Babson, P.W. Beatty, A.E. Brodie, W.W. Ellis, D.W. Potter, Anal. Biochem. 106 (1980) 55

[46] I. Messana, D.V. Rossetti, F. Misiti, F. Vincenzoni, E. Tellone, B. Giardina, M. Castagnola, Electrophoresis 21 (2000) 1606. 